\title{
Justified Group Belief Is Evidentially Responsible Group Belief
}

\author{
Paul Silva Jr. \\ psilvajr@gmail.com
}

September 21, 2017

Key Words: groups, justification, responsibility, belief

What conditions must be satisfied if a group is to count as having a justified belief? Jennifer Lackey (2016 Phil Review) has recently argued that any adequate account of group justification must be sensitive (in certain ways) to both the evidence actually possessed by enough of a group's operative members as well as the evidence those members should have possessed. I first draw attention to a range of objections to Lackey's specific view of group justification and a range of concrete case intuitions any plausible view of group justification must explain. I then offer an alternative view of group justification where the basic idea is that group justification is a matter of groups responsibly responding to their total evidence. This view both avoids the problems facing Lackey's account and also explains the relevant concrete case intuitions.

\section{Introduction}

One doesn't have to look hard to find ascriptions of group belief. We've all heard claims like: "The present administration believes that it's doing a good job," or "The psychology department regards its discipline as among the most important in the university," or "It's the opinion of the board of directors that new leadership is needed," or "It's the view of the subcommittee that the proposed reform would be disastrous." Each italicized expression is a way of ascribing a belief to a group, and just as an individual's belief can be justified or unjustified so can a group's belief. 
What does it take for a group to have a justified belief? After arguing against a range of alternative views, Lackey advises we adopt a view of group justification that is (in certain ways) sensitive to both the evidence actually possessed by enough of a group's operative members ${ }^{1}$ as well as the evidence those members should have possessed. The motivation for this later condition stems from cases where a group's members have duties to possess certain evidence in virtue of being members of their group, and the flouting of these duties by the members seems to negatively impact the group's justification. Accordingly, Lackey advises we adopt a view of group justification that is both evidentialist and responsibilist in spirit. Here is Lackey's (2016: 381) specific way of doing this:

\section{Group Epistemic Agent Account (GEAA)}

A group $\mathrm{G}$ justifiedly believes that $\mathrm{P}$ iff:

(1) A significant percentage of the operative members of $\mathrm{G}$ (a) justifiedly believe that $\mathrm{P}$, and (b) are such that adding together the bases of their justified beliefs that $\mathrm{P}$ yields a belief set that is coherent, and

(2) (a) Full disclosure of the evidence relevant to the proposition that $\mathrm{P}$, (b) accompanied by rational deliberation about that evidence among the members of $G$ (c) in accordance with their individual and group epistemic normative requirements, would not (d) result in further evidence that when added to the bases of G's members' beliefs that P, yields a total belief set that fails to make [it] sufficiently probable that $\mathrm{P}$.

But here is an alternative:

Evidentialist Responsibilism for Groups (ERG)

A group, G, justifiedly believes that $\mathrm{P}$ on the basis of evidence $\mathrm{E}$ iff:

(1) $\mathrm{E}$ is a sufficient reason to believe $\mathrm{P}$, and the total evidence possessed by enough of the operative members of $\mathrm{G}$ does not include further evidence, $\mathrm{E}^{*}$, such that $\mathrm{E}$ and $\mathrm{E}^{*}$ together are not a sufficient reason to believe $\mathrm{P}$, and

\footnotetext{
${ }^{1}$ The basic idea behind the target concept of an "operative member" is that not all members of groups seem to have a role in fixing what a group believes or what a group justifiedly believes. The operative members are just those members that do have such a role (Tuomela 2004: 113; Lackey 2016: 350).
} 
(2) $\mathrm{G}$ is epistemically responsible in believing $\mathrm{P}$ on the basis of E.

I aim to make two distinct contributions in what follows. First, I aim to show that ERG is at least as theoretically appealing as GEAA in its ability to address the relevant concrete cases that GEAA was constructed to address. Second, I aim to show how ERG is more appealing than GEAA due to its ability to avoid a range of objections facing GEAA. So even if some readers have only a modest degree of sympathy for the objections I offer against GEAA, the argument Lackey offered on behalf of GEAA will be undermined to the extent that ERG can do the same work that GEAA was forged to do.

\section{Evidential Constraints on Justified Group Belief}

Before introducing problems for GEAA and the alternative view of group justification that avoids them, it will help us to first reflect on some of the case-driven insights that motivated GEAA to begin with. Each case is inspired by Lackey's (2016) work, and while she discusses additional cases relevant to the assessment of alternative views of group justification I do not have the space to discuss all of her cases here. I've selected what I take to be the primary kinds of cases. Moreover, once the evidentialst-responsibilist alternative to GEAA is explained (section 4) and shown to address the cases discussed here, it will be clear how the evidentialstresponsibilist alternative to GEAA can also address the remaining cases discussed by Lackey.

What criteria ought a theory of justified group belief satisfy? First, it seems like it should be possible for a group to justifiedly believe $\mathrm{P}$ when the members of the group justifiedly believe $\mathrm{P}$ on different evidential bases. Take the following example:

Different Evidential Bases. A painting might have been stolen.

It's known that if it was stolen there are only three possible theifs and each is named 'Hank': Hank1, Hank2, and Hank3. A team of three detectives are investigating this possible theft: Detective1, Detective2, and Detective3. Detective1 has evidence E1 that entails (H1) that only Hank1 stole the painting; Detective2 has a distinct body of evidence E2 that also entails H1; and Detective3 has a distinct body of evidence E3 that also entails H1. None of the detectives have any counterevidence to $\mathrm{H} 1$ nor does any detective have any evidence that would defeat the 
probative force of any other detective's evidence. When the detectives confer with each other they don't share the details of their evidence, they simply share the fact that their evidence strongly supports the claim that (S) someone stole the painting. So the team of detectives believes $\mathrm{S}$.

Plausibly, the team of detectives not only believes $\mathrm{S}$, it also justifiedly believes S. This is not compromised by the fact that its members have not disclosed all of their information to each other. While it may seem odd that a group's members would arrive at a view about $\mathrm{S}$ without disclosing all their relevant evidence, it's easy to imagine various pressures that would reasonably prevent them from doing so: maybe understanding each member's evidence requires an expertise in an area the other members lack, maybe sharing their evidence would take more time than they have given their case load, maybe they're geographically separated and can only communicate through very brief messages. While such conditions may prevent the sharing of evidence, it needn't prevent them from co-ordinating their collective belief in $\mathrm{S}$ in a way that is responsive to the probative force of their total evidence: for the evidence each detective has supports H1, and thus also supports S, and they each believe $\mathrm{H} 1$ and $\mathrm{S}$ because of their evidence. The lesson to draw from this case is that:

LESSON\#1: It's possible for a group to justifiedly believe $\mathrm{P}$ even if each member of the group justifiedly believes $\mathrm{P}$ on a different evidential basis.

This lesson is very widely accepted among social epistemologists who have written on justified group belief. ${ }^{23}$

\footnotetext{
${ }^{2}$ For example, Schmitt's (1994) joint acceptance account of justified group belief, Goldman's (2014) account, and Lackey's (2016) group epistemic agency account all entail Lesson\#1 and that, other things being equal, the team of detectives in Different Evidential Bases is justified despite not having shared their evidence. Explaining why each account involves this implication in adequate detail would take more space than can be permitted here.

${ }^{3}$ It might seem like one of the upshots/presuppositions of cases like Different Evidential Bases is that groups can possess evidence in virtue of their members possessing it even though it's false that all or most of the members possess that evidence. This would refute a kind of summativism about group possession of evidence. But I don't see an immediate problem for such summativists here. For there's a difference between evidence E impacting the rationality of one's belief in $\mathrm{P}$ because one possesses evidence $\mathrm{E}$, and evidence $\mathrm{E}$ impacting the rationality of one's belief in $\mathrm{P}$ because someone else possess evidence $\mathrm{E}$ and one stands in an epistemically important relation to that other person. Testimony is a great example of this. Suppose an expert tells me there is conclusive evidence that $\mathrm{P}$, and I have no reason to distrust her. I now stand in a testimonial relation to the expert who possesses that conclusive evidence, and it's my relation to that expert and her evidence that impacts the rationality of my attitude towards P. But the evidence doesn't impact my attitude because I possess the evidence. The evidence might be from areas of theoretical physics that I couldn't possibly understand, and hence I'm not in a position to possess it. This is one way to
} 
Nevertheless, it's implausible that every time a group's members justifiedly believe $\mathrm{P}$ on some basis the group justifiedly believes $\mathrm{P}$. Take for example the following, Lackey-inspired (2016: 361) case:

Conflicting Evidential Bases. A painting might have been stolen. It's known that if it was stolen there are only three possible theifs and each is named 'Hank': Hank1, Hank2, and Hank3. A team of three detectives are investigating this possible theft: Detective1, Detective2, and Detective3. Detective1 has evidence E1 that strongly supports (H1) that only Hank1 stole the painting, Detective2 has evidence E2 that strongly supports (H2) that only Hank2 stole the painting, and Detective3 has evidence E3 that strongly supports (H3) that only Hank3 stole the painting. While H1, H2, and H3 are mutually incompatible, they each entail (S) that someone stole the painting. So each detective believes S. But when the detectives confer with each other they don't share the details of their evidence; they simply share the fact that their evidence strongly supports the claim that $\mathrm{S}$ is true: someone really did steal the painting. So the team of detectives believes S.

But notice that each detective possesses evidence that strongly supports that every other detective's evidence is misleading since each detective's evidence strongly supports that exactly one (different) person stole the painting. That is, Detective1's evidence, E1, strongly supports that $\mathrm{H} 1$ is true and that $\mathrm{H} 2$ and $\mathrm{H} 3$ are false; Detective2's evidence, E2, strongly supports that H2 is true and that H1 and H3 are false; and Detective3's evidence, E3, strongly supports that H3 is true and that H1 and H2 are false. So the total evidence possessed by the group's members supports inconsistent propositions, and the total evidence possessed by the group's members

think about what's going on in cases like Different Evidential Bases: even if a group cannot be said to possess the evidence that it's members possess, the fact that the members possess that evidence and the fact that the members stand in an epistemically important relation to the group, ensures that the evidence possessed by its members impacts the rationality of the group's belief. In the case of testimony we have a good idea of what that epistemically important relation is: it's the testimonial relation (whatever exactly it is). In cases like Different Evidential Bases it's not plausible to think of this in terms of a testimonial relation since the evidence isn't shared among the members. One could argue that it's a (non-summativist) group possession relation. Alternatively, one could deny that it's a possession relation at all. One way of doing this would be to hold that the relation is something like a bare normative transmission relation, where the normative force of the evidence possessed by the members gets transmitted to the group even though the possession relation is itself not transmitted to the group. This final option is one I suspect summativists would be inclined towards, and it shows a general way in which one could be a summativist about group evidence possession while still accepting the force of Different Evidential Bases. 
fails to support H1, or H2, or H3 and thus fails to support S. ${ }^{4}$

Nevertheless, each individual detective seems justified in believing $\mathrm{S}$ because each detective has sufficient evidence for believing $\mathrm{S}$ due to the fact that each detective has evidence that strongly supports $\mathrm{S}$, and each detective is unaware of the defeating counterevidence possessed by their colleagues. Thus, one might be tempted to think that if each individual member justifiedly believes $S$ on the basis of their evidence, then the group must also justifiedly believe $\mathrm{S}$.

But Lackey (2016) argues that we should resist this judgement. There are a few reasons for this to be gleaned from her insightful discussion. First, it's not at all intuitively obvious that the group of detectives is justified in Conflicting Evidential Bases. So there's not a lot of intuitive motivation stemming from our concrete case intuitions. Second, maintaining that the group of detectives is justified conflicts with plausible ideas about the nature of epistemic justification. For notice that the total evidence possessed by the group doesn't support $\mathrm{S}$ because the probative force of each body of evidence that supports $\mathrm{S}$ is undermined by evidence possessed by some other member. It is counterintuitive that a theory of group justification would imply that a group could be justified in believing $\mathrm{S}$ when the total body of evidence it is relying on (through its members) doesn't actually support S. This not simply counterintuitive, but it also seems to generate an implausible asymmetry between group and individual justification. For in the individual case, when a subject's justified belief is evidence-dependent, one's belief is justified only if one's total evidence supports one's belief. ${ }^{5}$ This is important for preserving the intuition that what is distinctive about epistemic justification is that it is a truth-conducive property. But if group justification is not constrained by the total evidence its members are relying on in some way, then the connection to truth for group justification will be so thin that it's hard to see how it's a genuine kind of epistemic justification. Since total evidence requirements for evidence-based justification are near universally endorsed, I expect most readers will have sympathy for (if not out-right endorse) the idea that the detectives in Conflicting Evidential Bases lack a justified belief.

So it's advisable to reject the idea that the team of detectives have a justified group belief in Conflicting Evidential Bases, and thus draw the following lesson:

\footnotetext{
${ }^{4}$ It is to be understood that as part of this case that no one member's evidence is more weighty than any others such that when their total evidence is pooled it provides sufficient support for exactly one hypothesis about the theft.

${ }^{5} \mathrm{I}$ cannot justifiedly believe $\mathrm{P}$ on the basis of just some of my evidence, $\mathrm{E}$, that supports $\mathrm{P}$ when $\mathrm{I}$ also have further evidence, $\mathrm{E}^{*}$, that defeats that original evidence. Knowing that Tweety is a bird is great evidence that Tweety flies. But I can't justifiedly believe Tweety flies if I have further evidence for thinking that Tweety had her wings cut. The later evidence defeats the former.
} 
LESSON\#2: The evidence possessed some member of a group can defeat the group's justification even if the rest of the group's members do not possess that evidence.

What the previous case shows is that the evidence actually possessed by the members of a group places limits on what a group can justifiedly believe even if the group fails to also possess that evidence.

But Lackey goes further. For she thinks that the evidence relevant to fixing a group's justification isn't limited to their possessed evidence. Rather, the evidence a group should have possessed also plays a role in determining what a group justifiedly believes. To appreciate this take the following Lackey-inspired (2016: 372-373) case:

\section{Group Epistemic Obligations}

Detectives1-3 spend just ten minutes gathering evidence. They know that they could easily-i.e. in a short amount of time with minimal effort-acquire more evidence that, for all they know, could impact the probative force of their total evidence on whether or not it's true $(S)$ that someone stole the painting. In that ten minutes each acquires evidence that strongly supports $\mathrm{S}$, but had they spent only five more minutes investigating they would have gained decisive counterevidence that proves $\mathrm{S}$ false (e.g. they would have found that the painting had been temporarily moved by the curator for an upcoming exhibit). But since they didn't do any further investigation, each of the detectives believes $\mathrm{S}$ is true and each is correct in thinking that $\mathrm{S}$ is supported by the total evidence they individually possess.

Again, while it's possible that the group of detectives believe S, it's implausible that the group could count as justifiedly believing S given their failure to adequately investigate whether $\mathrm{S}$ is true. For, as Lackey (2016: 373ff) points out, if there is evidence that one should have had which would have defeated one's justification if one possessed it, then one's justification is defeated. ${ }^{6}$ Thus:

LESSON\#3: Even if a group's possessed evidence provides sufficient support for believing $\mathrm{P}$, a group can fail to have a justified belief in $\mathrm{P}$ if the members of the group should have possessed further evidence.

To summarize: an adequate theory of justified group belief must explain Lessons\#1$\# 3$ by explaining our intuitive verdicts about the specific cases that gave rise to those

\footnotetext{
${ }^{6}$ For further defense of the significance of evidence one should have had see Goldberg (forthcoming a; forthcoming b).
} 
lessons. GEAA is one way of accommodating these insights. Due to considerations of space I will leave it to the reader to see Lackey's (2016: 379ff) explanation of just how GEAA accommodates cases like those discussed above. In what follows I offer an alternative account of group justification that can do the same work as GEAA relative to the cases discussed above while also avoiding each of GEAA's problems.

\section{Trouble for GEAA}

GEAA faces three problems. The first two problems involve under-appreciated cases where justified group belief diverges from the beliefs of its members. The third problem concerns the counterfactual condition that GEAA relies on. Each problem for GEAA generates a new desideratum for an adequate theory of justified group belief.

Caveat: I believe each of the problems to follow are intuitively well-motivated and if one's theory of group belief cannot make sense of these cases, so much the worse for one's theory of group belief. Moreover, I'm inclined to think the first two problems make the most sense on non-summativist views of group belief, ${ }^{7}$ especially those that emphasize the role of members' joint commitment. ${ }^{8}$ Thus I think these cases provide a bit of confirmation for versions of non-summativism that are able to naturally explain the possibility of such cases. I say only "a bit of confirmation" because I suspect there are modest maneuvers available to those with alternative views of group belief that can help them make sense of the cases to follow. However, I must set these questions about the metaphysics of group belief to the side; it is enough of a task to address questions about the epistemology of group belief. ${ }^{9}$

\subsection{Divergence Problems for GEAA(1)(a): Proper Basing}

Let's start with GEAA(1)(a). This condition tells us that a group can justifiedly believe $\mathrm{P}$ only if the operative members of the group justifiedly believe $\mathrm{P} .{ }^{10}$ Lackey

\footnotetext{
7 ...where "non-summativist" views of group belief are broadly taken to be ones that don't make a group's belief in $\mathrm{P}$ a simple function from most or all of a group's relevant members believing $\mathrm{P}$. ${ }^{8}$ Cf. Gilbert (1987; 1989: 288ff), Gilbert and Pilchman (2014: 195), and Tuomela (1995).

${ }^{9} \mathrm{~A}$ referee pointed out to me that even if the cases I discuss below are neutral on views of group belief, they seem to have implications for views about a group's possession of evidence. Specifically, they seem inconsistent with a kind of summativist view of group evidence possession. I address this issue in footnote 3 .

${ }^{10}$ A referee suggested to me that some may think GEAA is ambiguous between the members believing $P$ personally and the members believing $P$ in their capacity as members. However, since personal (=private, individual) belief is the standard sense of belief one conveys when attributing a
} 
(2016: 342) states that her term 'justifiedly believes' refers to group doxastic justification, i.e. the justification a group has for a belief they actually hold. The trouble is that there are intuitive cases where none of a group's members are doxastically justified in believing $\mathrm{P}$ while the group is doxastically justified in believing P. Such cases exist because a group can respond to the evidence its members possess in a way that differs from how each member individually responds to that evidence. Thus, it's possible for there to be cases where a group properly responds to the relevant body of evidence possessed by its members while the members themselves do not properly respond.

Before outlining one such case, it will be helpful to reflect on Turri's recent work on what it takes to have a doxastically justified belief. Consider the following sufficient condition for having a (doxastically) justified belief:

(Basis) If evidence $\mathrm{E}$ is $\mathrm{S}$ 's source of justification to believe $\mathrm{P}$, and $\mathrm{S}$ believes $\mathrm{P}$ on the basis of $\mathrm{E}$, then $\mathrm{S}$ has a (doxastically) justified belief in P. ${ }^{11}$

While (Basis) has been endorsed by many epistemologists, many have also rejected it. ${ }^{12}$ The sorts of cases that have led to its rejection are cases where agents respond to their evidence in support of believing $\mathrm{P}$, but their way of responding to their evidence is epistemically problematic. Here's one case Turri (2010: 315-316) uses to illustrate the point:

"belief" to an individual, I suspect Lackey would have made it clear if she wanted us to understand something other than personal belief when she attributes beliefs to individuals. Moreover, many of Lackey's counterexamples are understood most naturally as cases where groups have/lack justification (at least in part) because their members have/lack a justified personal belief. Additionally, GEAA seems threatened by cases that Lackey herself provides if (1)(a) were understood in terms of members' believing $P$ in their capacity as members. For example, take Lackey's (2016: 351) Philip Morris case: Ignoring Evidence. In that case it's intuitive not only to think that Philip Morris is not justified in not believing $(\mathrm{O})$ that the dangers of smoking give the company a reason to believe that warning labels should be placed on cigarette boxes, it's also intuitive to think Philip Morris also justifiedly believes O. But then Philip Morris has a justified belief in O even though its members do not believe $\mathrm{O}$ in their capacity as members (= the members do not jointly accept $\mathrm{O}$ ). But that's inconsistent with GEAA. So there are a few reasons to prefer the personal belief reading of (1)(a). (The idea that in Lackey's Philip Morris case the jury believes O might seem inconsistent with joint acceptance theories of group belief since the jury's members don't jointly accept O. But there are two ways of being a joint acceptance theorist: holding that joint acceptance by a group's members is necessary for group belief, and holding that while it's sufficient for group belief, other conditions may also be sufficient. Only the necessity claim is threatened by the Philip Morris case. This raises issues concerning the nature of group belief that I cannot hope to adequately delve into here.)

${ }^{11}$ See Turri (2010) for discussion of the pedigree of this condition.

${ }^{12}$ Here are some folks who have rejected it: Armstrong (1973: 98), Swain (1988: 467), Millar (1991: 57), Wedgwood (2014), Goldman (2012: 7), [author a, b, c], Sylvan and Lord (forthcoming), and Smithies (2015). 


\section{MISS IMPROPER}

Consider two...jurors, Miss Proper and Miss Improper, sitting in judgment of Mr. Mansour. Each paid close attention throughout the trial. As a result, each knows the following things:

(P1) Mansour had a motive to kill the victim.

(P2) Mansour had previously threatened to kill the victim.

(P3) Multiple eyewitnesses place Mansour at the crime scene.

(P4) Mansour's fingerprints were all over the murder weapon.

$<$ Mansour is guilty $>$ is propositionally justified for both jurors because each knows (P1-P4). As it happens, each comes to believe $<$ Mansour is guilty $>$ as the result of an episode of explicit, conscious reasoning that features (P1-P4) essentially. Miss Proper reasons like so:

(Proper Reasoning) (P1-P4) make it overwhelmingly likely that Mansour is guilty. (P1-P4) are true. Therefore, Mansour is guilty.

Miss Improper, by contrast, reasons like this:

(Improper Reasoning) The tea leaves say that (P1-P4) make it overwhelmingly likely that Mansour is guilty. (P1-P4) are true. Therefore, Mansour is guilty.

... [yet] only Miss Proper's belief that Mansour is guilty is doxastically justified.

Many have since followed Turri in taking cases like this to refute (Basis). For it's clear that on the usual accounts of the basing relation (as a causal or counterfactual or doxastic relation of some sort) that Miss Improper's belief can be based on (P1-P4). So, given that her knowledge of (P1-P4) generates propositional justification to believe that Mansour is guilty, (Basis) entails that her belief can be doxastically justified if she bases her belief on her knowledge of (P1-P4). But what Turri has observed is that Miss Improper's use of her evidence is, well, improper. She uses her evidence to form her belief in Mansour's guilt in a way that is epistemically inappropriate and cannot yield a doxastically justified belief.

It's a simple trick to transform the case of Miss Improper into an objection to $\operatorname{GEAA}(1)(\mathrm{a})$. Take a jury in which every juror responds to their evidence as 
Miss Improper does, i.e. every juror arrives at the belief that Mansour is guilty via Improper Reasoning. Yet every juror also recognizes that as jurors they should ignore the tea leaves in the sense that tea leaf readings should not figure into their collective deliberations. For every juror respects the fact that only court presented evidence should be used in the context of legal deliberations. So when the jury members deliberate they never once include their private views about the tea leaves in their discussions nor do they in any other way take the tea leaves into account in arriving at a collective position on Mansour's guilt. Rather, when they deliberate as a group and reach the view that Mansour is guilty they reach it in the same way that Miss Proper does. Thus, when the jury reports on its belief that Mansour is guilty the jury explains how they arrived at that belief in the following way:

It is the view of this jury that Mansour guilty. We hold this view because (P1-P4) make it overwhelmingly likely that Mansour is guilty, and (P1-P4) are true.

So here we have a case where the group holds a doxastically justified belief because it properly responds to its evidence, while no member of the group properly responds to its evidence. So no member of the group is doxastically justified. But this is inconsistent with GEAA(1)(a)'s requirement that at least some of the group's operative members be doxastically justified. Accordingly, GEAA is unable to accommodate the thought that group and member doxastic justification can diverge in this case. ${ }^{13}$

\footnotetext{
${ }^{13} \mathrm{~A}$ referee pointed out to me that some might worry that the fact that the jury's members only employ Proper Reasoning when acting in their capacity as jury members, suggests that the jury members also come to believe Mansour is guilty in response to Proper Reasoning. This would suggest that the personal beliefs of the jury members then become doxastically justified.

Doubtless it is possible that someone who first started out personally believing in Mansour's guilt via Improper Reasoning could subsequently revise how they hold their personal belief upon considering Proper Reasoning and coming to recognize that it is epistemically adequate reasoning. But undercutting the objection to GEAA at this point requires that it be impossible for a subject not to hold a personal belief in response to reasoning that they recognize as epistemically adequate. Not only is this impossibility claim not clearly right, it's inconsistent with the idea that part of what it is for one to hold one's personal belief in response to some form of reasoning is for that form of reasoning to (at least partially) cause one to hold/sustain that personal belief. But causal relations are contingent. In which case it's false that just because one recognizes an additional form of reasoning as adequate for holding a personal belief that one will inevitably thereby come to hold that personal belief in response to that reasoning. So it seems possible for an agent to first form a personal belief in response to bad reasoning, learn of the good reasoning, and not then come to maintain their personal belief in response to the good reasoning.
} 


\subsection{Divergence Problems for GEAA(1)(a): Beliefs}

GEAA(1)(a) tells us that a group's beliefs are limited to the beliefs of its operative members. Thus, if no operative member believes $\mathrm{P}$, then the group does not believe $\mathrm{P}$ either. But there are some cases where it seems plausible that a group justifiedly believes that $\mathrm{P}$ even if no one in the group believes that $\mathrm{P}$. While some cases of divergence in belief are not all that intuitive,${ }^{14}$ some are quite credible. For example:

\section{Hidden Belief Revisions}

A corporate board is trying to determine whether $\mathrm{P}$, and so it has jointly evaluated the evidence for P. After their deliberations every board member comes to believe $\mathrm{P}$ solely because their total evidence strongly supports believing $\mathrm{P}$, and every board member publicly expresses this fact at the board meeting. Because of this each board member comes to know that every other board member believes $\mathrm{P}$ solely on the basis of their shared evidence, which strongly supports believing $\mathrm{P}$.

So in the board's attempt to figure out whether P every board member came to believe $\mathrm{P}$ just on the basis of their evidence, and every board member came to know that every other member believes P. Because of this it is hard to reject the idea that the board itself believes P. Our story now continues:

... Days later each board member begins to doubt himself/herself. This rising doubt is owed to the fact that their evidence was very complicated and difficult to keep in mind all at once without having various graphs and charts in front of them. So every board member ends up suspending belief in $\mathrm{P}$ rather than trusting their earlier judgement. Despite this, each member of the board still believes that every other member of the board continues to believe P-since that was every member's view at the end of their deliberations. So when each member is asked what the board's view is about P, every member will assert that the view of the board is that $\mathrm{P}$ is true; and when each board member has to draw inferences when reasoning on behalf of the board they will do so on the basis of $\mathrm{P}$; and when each member is called upon to act on behalf of the board every member will act on P. Nevertheless none of the board members now believe that $\mathrm{P}$ is true for every board member has suspended belief in $\mathrm{P}$.

\footnotetext{
${ }^{14}$ Lackey (2016: 344ff) for example discusses one such case from Schmitt (1994) involving a jury who is instructed to ignore a bit of evidence $\mathrm{E}$.
} 
In these circumstances it's intuitive to think that the board continues to believe $\mathrm{P}$ even though all of the board members have ceased to believe P. Notice how this judgement fits with familiar observations about the function of belief: belief is a state that's crucially connected to assertion, inference, and action. That is, when one believes that $\mathrm{P}$ one's in a state that, other things being equal, disposes one to assert that $\mathrm{P}$, draw inferences in a way that presupposes the truth of $\mathrm{P}$, and act on P. ${ }^{15}$ Notice that these characteristics are characteristics that the board retains in the example above. For when operating in their role as a board member each board member will, other things being equal, assert that $\mathrm{P}$, draw inferences from $\mathrm{P}$, and act on $\mathrm{P}$. Yet outside of their role as board members they will not assert P, draw inferences from $\mathrm{P}$, or act on $\mathrm{P}$ since they have each suspended belief in $\mathrm{P}$.

Does the board justifiedly believe that $\mathrm{P}$ once each member has suspended belief? Here it is plausible to think that the board does continue to justifiedly believe P. For it's not as if the board's present belief in $\mathrm{P}$ is now floating free of its evidence; rather, it's the board's past responsiveness to its total evidence that is responsible for its present belief. So it's plausible to think that the board does justifiedly believe P. But then GEAA has a problem. For GEAA(1)(a) implies that at least some board members must justifiedly believe P. But none of them do because none of them have a belief in $\mathrm{P}^{16}$ So once again GEAA has a problem. ${ }^{17}$

\subsection{Problems for GEAA(2)}

Recall GEAA(2) tells us that a group G justifiedly believes P only if:

(2) (a) Full disclosure of the evidence relevant to the proposition that $\mathrm{P}$,

(b) accompanied by rational deliberation about that evidence among the members of $\mathrm{G}$ (c) in accordance with their individual and group epistemic normative requirements, would not (d) result in further evidence that when added to the bases of G's members' beliefs that $\mathrm{P}$, yields a total

\footnotetext{
${ }^{15}$ Wedgwood (2012) and Wesiberg (2016).

${ }^{16}$ Notice that the claim is not that each member is justified in suspending belief. Indeed, I suspect a plausible case can be made for some kind of historical reflection principle along the following lines: other things being equal, if one knows that one's past self believed $\mathrm{P}$ and one's past self was more informed than one's present self, and one has no new relevant information, then one is rationally required to believe $\mathrm{P}$.

${ }^{17}$ There are further putative cases in the literature where no member of a group believes $\mathrm{P}$ though the group does believe P (Bird 2014: 57; Gilbert 1989: 288ff; Gilbert and Pilchman 2014: 195). In some of these cases the group at no point in their history ever believed P. These cases threaten GEAA in the same way. But in conversation with others I've found that such cases are much less compelling than the case described above.
} 
belief set that fails to make [it] sufficiently probable that P.

There are two things to notice about this condition. First, it's just a bit vague on what counts as an adequate amount of deliberation. For example, some evidence might only emerge in the course of months or years of deliberation. Is group justification truly hostage to what evidence would emerge were the group to spend months or years considering an issue? Perhaps this is sometimes the case. But there are surely other times where the possibility of acquiring evidence after a very long period of deliberation is not epistemically relevant to one's presently having a justified belief. What about shorter periods of deliberation, e.g. weeks or days or hours? The concern is that any line one draws in the sand will seem arbitrary. But perhaps there are contextual factors that can in some principled way draw these lines. I just want to note that providing some story here is important.

The second thing to notice about condition (2) is that it's a would-not counterfactual. So take the relevant conditions from (2):

(a)-(c): Enough of the operative members of group, G, fulfill their epistemic duties ( $q u a$ group and qua individuals) and they fully disclose their relevant evidence, $\mathrm{E}$, and deliberate over it.

(d): No further evidence, $E^{*}$, emerges in the course of that deliberation that makes G's total evidence, E\&E*, for $\mathrm{P}$ such that $\mathrm{P}$ is not sufficiently probable on E\&E*.

Given the standard semantics for counterfactual conditionals, (2) is true only if the space of nearby worlds is such that: if (a)-(c) obtain at a nearby world, then (d) also obtains at that world.

But notice how demanding this is. Suppose (a)-(c) are satisfied at a nearby non-actual world, and that at this world enough operative members discover a sophisticated line of reasoning that leads to strong evidence, $\mathrm{E}^{*}$, against P. However, the sophistication of the line of reasoning makes it unlikely that any of them would discover it-that is, at most of the nearby worlds they don't discover this line of reasoning. So suppose the actual world is like this: due to the sophistication of the line of reasoning no member of the group discovers the counterevidence $\mathrm{E}^{*}$ in deliberation after each member has disclosed their evidence. Does the fact that there are some few nearby non-actual worlds where the operative members do discover the sophisticated line of reasoning that leads to $\mathrm{E}^{*}$ really imply that in the actual world the group fails to justifiedly believe P? The idea that it does will doubtless strike many as implausible. 
For contrast, consider how implausible this is in the individual's case. For it seems possible for an individual to have a justified belief in $\mathrm{P}$ on the basis of evidence $\mathrm{E}$ at a time, and have that justified belief overturned so that one comes to justifiedly believe not-P at some later time only because one's further a priori reflection on $\mathrm{E}$ surfaces further evidence $\mathrm{E}^{*}$ such that $\mathrm{E}$ and $\mathrm{E}^{*}$ justify not believing P. For example, suppose a known highly reliable testifier says that evidence E supports believing $\mathrm{P}$, and having never considered E before I trust her and I believe that E supports believing P. On standard views of testimonial justification I can then justifiedly believe that E supports believing $\mathrm{P}$ even if $\mathrm{E}$ does not actually support believing $\mathrm{P}$-justification is fallible after all. However, suppose that I find E really interesting and keep reflecting on it's relation to P. But after a good deal of a priori reflection on E and it's inferential relations to P I realize that the testifier got it wrong: E does not support believing P. I now justifiedly reject the proposition that E supports believing $\mathrm{P} .^{18}$

But the idea that I could initially be justified in my belief that E supports $\mathrm{P}$ on the basis of testimony, while I later become justified in not believing that E supports $\mathrm{P}$ due to my reflection on E's inferential relations to $\mathrm{P}$ is at odds with a condition like GEAA(2) when applied to the individual's case. ${ }^{19}$ But if a condition parallel to GEAA(2) doesn't hold in the individual's case, why should GEAA(2) hold in the group case?

Now it may well be that group and individual epistemology can separate in such a way that principles that hold in individual epistemology don't have counterparts that hold in group epistemology. But GEAA(2) is not clearly one of them. For suppose I was part of a research team and that I and the other members jointly came to believe that $\mathrm{E}$ supports $\mathrm{P}$ solely on the basis of the testimony I initially recieved. Then suppose that at some time later, due solely to my further reasoning which yielded further evidence against the idea that E supports $\mathrm{P}$, that group came to believe that E does not support believing P. In such a case it's hard to see what relevant difference there could be between my individual case and the group case such that early on I was justified in believing that $\mathrm{E}$ supports $\mathrm{P}$ on the basis of testimony, but my group was not justified in believing that E supports P. Again, it seems like we need something other than GEAA to explain what grounds group

\footnotetext{
${ }^{18}$ If one is worried about implicit assumptions that lead to controversial views about peer disagreement, just suppose that the testifier is an epistemic inferior. Epistemic inferiors can still be valuable sources of information via testimony.

${ }^{19}$ Given the vagaries of the temporal dimension of GEAA(2), compress my story into whatever you feel like the right length of deliberation happens to be for GEAA(2) to be a plausible condition.
} 
justification.

\section{Evidentialist Responsibilism for Groups: Expla- nation}

One thing we learned from the previous sections is that group justification has to be responsive to the evidence possessed by its members even if the members of the group have not shared that evidence with each other. This is a kind of evidentialist constraint on group justification. Another thing we learned from the previous sections is that group justification has to be constrained by epistemically responsible agency, i.e. members cannot achieve justification for their group on the cheap by failing to fulfill their relevant epistemic obligations. This is a kind of responsibilist constraint on group justification.

GEAA is one way of uniting these two constraints, but here is another:

Evidentialist Responsibilism for Groups (ERG)

A group, G, justifiedly believes that $\mathrm{P}$ on the basis of evidence $\mathrm{E}$ iff:

(1) $\mathrm{E}$ is a sufficient reason to believe $\mathrm{P}$, and the total evidence possessed by enough of the operative members of $\mathrm{G}$ does not include further evidence, $\mathrm{E}^{*}$, such that $\mathrm{E}$ and $\mathrm{E}^{*}$ together are not a sufficient reason to believe $\mathrm{P}$, and

(2) $\mathrm{G}$ is epistemically responsible in believing $\mathrm{P}$ on the basis of E.

In the remainder of this section I'll explain how ERG is to be understood. As I will note at the end of this section, just how one fills out the details of ERG's conditions will depend a bit on one's further theoretical commitments. Since I cannot here hope to settle all the collateral issues that a maximally precise filling out of ERG depends on, I will sketch some directions different theorists may be inclined towards. But even though some aspects of ERG will remain just a bit schematic it will become clear in the next section that ERG can avoid GEAA's problems as well as explain our judgements about the concrete cases of the previous section.

The first thing to notice about ERG is that its scope is limited by its left-hand side: its concern is only with justified group beliefs that are based on evidential considerations. Thus ERG leaves open the possibility of a more general account of group justification that permits some non-evidence-based justified group beliefs. 
After all, if one rejects evidentialism in the case of individual justification (as many epistemologists do) then one should be at least open to the idea that evidentialism fails for groups also. I find grappling with evidence-based group justification a sufficiently challenging task, so I limit my focus to it. ${ }^{20}$

Second, according to ERG(1) the total evidence relevant to the justification of the group's belief is not all the evidence possessed by every member-at least not in every case. For some group members will not be operative members, and sometimes there will be evidence that is not possessed by enough of the operative members for it to be part of the pool of total evidence relevant to evaluating a group's justification. How many, or what percentage, of operative members need to have evidence $\mathrm{E}$ in order for E to be part of that pool of evidence? Like Lackey, I will leave this vague because settling these questions likely depends on the nature of the group in question and the specific functions of their operative members. Sometimes it may be enough that one operative member-perhaps the group's leader-possesses E for E to be part of the total relevant evidence. Other times, it might be that more members need to possess $\mathrm{E}$ for $\mathrm{E}$ to be part of the total evidence relevant to a group's justification.

The third thing to note about ERG(1) is that it makes a group's justification sensitive to defeaters. For even if a subset of the total evidence, E, provides strong support for believing $\mathrm{P}$, it may be that the total evidence includes (rebutting, undercutting, or normative) defeating evidence, $\mathrm{E}^{*}$, such that $\mathrm{E} \& \mathrm{E}^{*}$ fail to give one sufficient reason to believe P. In such cases ERG(1) will not be satisfied, and so ERG will not imply that a group has a justified belief in such cases. It is this feature of ERG that does the work that GEAA(1)(b) was intended to do. For that condition was intended to accommodate the insight that a group could justifiedly believe $\mathrm{P}$ only if its members' evidence supported a coherent set of beliefs. Take the uncontroversial assumption that one's total evidence doesn't provide one with sufficient reason to believe $\mathrm{P}$ if one's total evidence provides equal support for believing $\mathrm{P}$ and also holding further attitudes that are incoherent with believing P. Given that assumption, EGR(1) can easily explain the insight that a group could justifiedly believe $\mathrm{P}$ only if the evidential bases of the group's members support a coherent set of beliefs that include believing $\mathrm{P} .^{21}$

\footnotetext{
${ }^{20}$ As GEAA is formulated it's unclear whether GEAA is consistent with the possibility of justified baseless beliefs (cf. Turri 2011; Goldman 2009). For GEAA seems to require that a justified group belief be based on something. But if it's possible for there to be justified beliefs that a group's members hold that are based on nothing, then GEAA seems to predict that the group cannot itself justifiedly hold that belief. Due to considerations of space I will not here develop this objection to GEAA.

${ }^{21}$ The importance of this is manifested in Lackey's (2016: 357ff; 382ff) Group Justification
} 
Now consider ERG(2). The first clarification concerns how we should understand a group basing a belief on its evidence as opposed to an individual doing so. Our discussion of concrete cases in section 2 suggests that the following is a plausible sufficient condition for group basing:

\section{Group Basing Condition}

A group's belief in $\mathrm{P}$ is based on evidence $\mathrm{E}$ at time $\mathrm{t}_{1}$ if: either

(a) at $t_{1}$ enough of the group's operative members believe (/are jointly committed to) $\mathrm{P}$ on the basis of $\mathrm{E}$, or

(b) if $\mathrm{E}=\mathrm{E} 1 \& \mathrm{E} 2 \& \ldots \& \mathrm{En}$ then: at $\mathrm{t}_{1}$ enough operative members believe (/are jointly committed to) $\mathrm{P}$ on the basis of some subset of E1-En, and E1-En are each part of the basis of enough of the operative member's belief in (/joint commitment

to) $\mathrm{P}$, or

(c) the group believes $\mathrm{P}$ at $\mathrm{t}_{1}$ because at some earlier time, $\mathrm{t}_{0}$, (a) or (b) obtained.

The parenthetical concerning 'joint commitment' in (a) and (b) are meant to illustrate how the present account of group basing being sketched can be massaged to fit different views of group belief. Simple summativist views (Quinton 1975; Cohen 1989) and certain judgement aggregation views (List and Pettit 2011) of group belief make group belief a function of its operative members' beliefs. In contrast, certain non-summativists about group belief reject the idea that group belief is a function of members' beliefs. Rather, they hold that a group can believe $\mathrm{P}$ even if few-to-none of its members believe $\mathrm{P}$; what matters for these non-summativists is that the group's members stand in some kind of pro-relation (e.g. joint commitment) to P such that the group counts as believing P (Gilbert 1987, 1989; Gilbert and Pilchman 2014; Bird 2014; Kallestrup forthcoming; Tuomela 1995, 2004). You can see why, then, it would be odd for such non-summativists about group belief to endorse a view of group basing that required members to believe $\mathrm{P}$ on the basis of $\mathrm{E}$ if a group's belief is to be based on E. Since I cannot here adjudicate between different views of group belief I invite readers to precisify the Group Basing Condition in a way that suits their theoretical preferences. In this regard, notice that the Group Basing Condition is only a sufficient condition. This is, again, because

Paradox. For considerations of space I've omitted discussion of this aspect of Lackey's paper. But it should be clear how ERG(1) addresses this concern. See Lackey (2016: 383-385) for a discussion of the notion of coherence. 
one's attitudes towards the metaphysics of group belief will tend to direct one to further and likely incompatible sufficient conditions. But even so, (a)-(c) remain intuitively plausible and they should be relatively uncontroversial on most views of group belief. Moreover, they're all we will need in what follows.

(a) captures the idea that a group can believe $\mathrm{P}$ on the basis of $\mathrm{E}$ just in virtue of enough of its members believing $\mathrm{P}$ on the basis of $\mathrm{E}$ (/enough of its members being jointly committed to $\mathrm{P}$ on the basis of $\mathrm{E}$ ). (b) captures the thought couched in Lesson\#1: that a group's belief in $\mathrm{P}$ can be based on evidence $\mathrm{E}$ (where E includes just E1-En) even though no member bases their belief (/joint commitment) on all of E1-En. Rather, it can be enough that each of E1-En is part of the basis of enough operative member's belief in (/joint commitment to) P. (c) captures a plausible tracing condition for group basing. By analogy, take the fact that my belief in the soundness and completeness of first-order propositional logic is based on the proofs for these found in standard logic textbooks. But it's been a while since I've thought about those; embarrassingly, I've mostly forgotten them! But I still believe them on the basis of the proofs in a derivative historical sense: I now believe them because I once fully understood the proofs and formed a belief on that understanding. So in this sense my present belief is based on the proofs. (c) expresses the same sort of thought for group belief. ${ }^{22}$

How should we understand ERG(2)'s responsibility condition? I propose we think of it in the following way:

\section{Group Responsibilist Condition}

A group, $\mathrm{G}$, is epistemically responsible in believing $\mathrm{P}$ on the basis of E iff (a) enough of the operative members of G satisfy their G-relevant epistemic duties, and (b) G properly bases its belief on E.

(a)'s idea of a G-relevant epistemic duty has to do with epistemic duties that a member of $G$ has in virtue of being a member of $G$ with a particular role in $G$. Think back to the detectives in Group Epistemic Obligations: in virtue of being a group of detectives on a case, each with an investigative role, each detective had an obligation to engage in a certain level of investigation in order to have a justified belief on the basis of their evidence. It's not hard to think of additional cases where one's membership and role within a group can bring on additional epistemic duties that one would not have had were they not a part of the group. For example, part

\footnotetext{
${ }^{22}$ See Goldman (2009) for defense of this kind of historical condition for justified belief in the individual's case.
} 
of being a faculty philosophy teacher responsible for grading student essays involves a duty to know the content of those essays; and being a lawyer on a defense team for a client brings with it a duty to know the particulars of the case. But were one not a philosophy teacher or a lawyer one would have no obligation what so ever to know these things. The claim of (a) is just that a group responsibly believes $\mathrm{P}$ only if its members satisfy the epistemic duties they have in virtue of being members of $\mathrm{G}$ with a particular role in $\mathrm{G}{ }^{2324}$

(b)'s idea of properly basing one's belief on one's evidence has to do with whatever it is that differentiates the case of Miss Proper from Miss Improper discussed above. What that case does for us is highlight the fact that there is some such difference; what that case does not do for us is explain what that difference consists in. Again, the scope and length of this project forces me to leave off the task of advocating for any particular view of that difference. ${ }^{25}$ However, since we saw above that it was intuitively plausible that a group could properly base its belief on evidence $\mathrm{E}$ while its members do not, we should expect an adequate theory of proper basing that is extended to groups to explain the possibility of such cases. ${ }^{26}$

Doubtless many readers will be discontent with the lack of specificity of certain aspects of my exposition of ERG, the Group Basing Condition, and the Group Responsibilist Condition. But this lack of specificity should not be seen as an ob-

\footnotetext{
${ }^{23}$ One thing to note about the Group Responsibilist Condition is that it doesn't matter what the result would have been had the members fulfilled their epistemic duties. For example, maybe the group believes $\mathrm{P}$ on $\mathrm{E}$ but had they fulfilled their epistemic duties they would have acquired further evidence, $\mathrm{E}^{*}$, such that $\mathrm{E} \& \mathrm{E}^{*}$ do support believing $P$. In such a case, the group is surely fortunate that both $\mathrm{E}$ and $\mathrm{E} \& \mathrm{E}^{*}$ support believing $\mathrm{P}$. But being so fortunate does not entail being responsible in the target sense.

${ }^{24}$ Again, see Lackey (2016) and Goldberg (forthcoming a, forthcoming b) for further discussion and defense for this generals sort of condition.

${ }^{25}$ For discussion of possible explanations see Neta (forthcoming), Smithies (2015), and xxxx.

${ }^{26}$ Here's an outline of a case worth thinking about in relation to the Group Responsibility Condition. Suppose a group's members each believe P on some subset of the group's total set of evidence, but it's only the total set of evidence that adequately supports P. Can the group justifiedly believe $\mathrm{P}$ on $\mathrm{E}$ if every member believes $\mathrm{P}$ on an inadequate piece of evidence? ERG as characterized above leaves it as a possibility that such a group has a justified belief. Notice that this is a lot like the divergence case from section 3.1, and part of what that divergence case teaches us is that not all of an individual's epistemic obligations need be satisfied if the group is to have a justified belief (see footnote 28). While granting a group justification in such a case might seem odd notice that it doesn't have the result that group justification floats free of the total evidence possessed by the operative members. Rather, ERG continues to ground group justification in that total evidence. This is what makes ERG immune to worries stemming from Lackey's (2016: 351) Philip Morris cases where members manipulate the evidence available to the group. What group justification floats free of according to ERG is the satisfaction of (at least some of) its member's individual epistemic obligations that are not also G-relevant obligations. But, should one wish, one could close off cases like this by treating the duty base a belief on adequate evidence as both an individual and a G-relevant obligation. I will leave this an open question for readers to ponder.
} 
jection. Compare the fact that many epistemologists first become persuaded by reflection on cases that knowledge requires justified true belief that avoids gettier cases while nevertheless lacking, or being uncertain about, what the best theory of justification, belief, and gettier cases happens to be. Just think of the on-going debates between Lockeans and non-Lockeans about outright belief, internalists and externalists about justification, safety theorists and sensitivity theorists about what goes wrong in gettier cases. While these are deep and persistent disagreements, epistemologists party to these disagreements still tend to agree that knowledge requires justified true belief that avoids gettier cases. My point in this paper is that ERG is a plausible view of group justification and that the Group Basing Condition and the Group Responsibilist Condition are plausible, if incomplete, ways of filling out the details in ERG.

\section{Evidentialist Responsibilism for Groups: Appli- cation}

As noted above, there are different ways different theorists may want to fill out certain details involved in ERG. Despite this we've now got a good enough grip on what kind of view ERG is to see how it can avoid the objections to GEAA from section 3 and accommodate the insights from the concrete cases discussed in section 2.

First, recall Lesson\#1 from Different Evidential Bases: it's possible for a group to justifiedly believe $\mathrm{P}$ even if each member of the group justifiedly believes $\mathrm{P}$ on a different evidential basis. ERG together with the Group Basing Condition offers an explanation of this. For, as discussed in the previous section, the Group Basing Condition(b) leaves it open that no operative member possesses all the of the evidence relevant to the justification of the group's belief. So there can be some cases where each member justifiedly believes $\mathrm{P}$ on a different evidential basis because no member has the same body of evidence.

ERG can also accommodate the specific judgement that the team of detectives in Different Evidential Bases has a justified belief in $\mathrm{S}$ for the following reasons. First, ERG(1) is satisfied in that case because the group of detectives' total evidence (E1, E2, and E3) supported believing S, and that total evidence did not include any further evidence that gave them sufficient reason to not believe S. Second, ERG(2) is satisfied in that case because there was (implicitly) no relevant epistemic duty that 
was flouted by the detectives, and because the group (implicitly) properly based its belief in $\mathrm{S}$ on its evidence.

Second, recall Lesson\#2 from Conflicting Evidential Bases: the evidence possessed some member of a group can defeat the group's justification even if the rest of the group's members do not possess that evidence. Notice that ERG entails this lesson because ERG(1) imposes the constraint that the group's justification is hostage to the total evidence possessed by enough of the group's operative members. Thus even if some operative members have evidence $\mathrm{E}$ that normally would be a sufficient reason to believe $\mathrm{P}$, if enough of the other operative members have evidence $\mathrm{E}^{*}$ such that $\mathrm{E} \& \mathrm{E}^{*}$ fail to be a sufficient reason to believe $\mathrm{P}$ then the group will not count as justifiedly believing $\mathrm{P}$.

It is this implication of ERG(1) that prevents ERG from having the counterintuitive implication that the team of detectives has a justified belief in Conflicting Evidential Bases. For in that case the total evidence possessed by the operative members of the group (which implicitly was all of the detectives) is such that it fails to give the group sufficient reason to believe $\mathrm{S}$-for each member's evidence was rebutted by some other member's evidence. Thus, ERG(1) enables ERG to explain both Lesson $\# 2$ and the intuitive judgement that the group of detectives lacks justification in Conflicting Evidential Bases. ${ }^{27}$

Third, recall Lesson\#3 from Group Epistemic Obligations: the fact that there is evidence that neither a group nor it's members actually possesses can prevent a group from justifiedly believing $\mathrm{P}$ if the members of the group should have possessed that evidence. ERG(2) and the Group Responsibilist Condition quite clearly enable ERG to explain this lesson. For ERG(2) limits group justification to groups whose beliefs are held in an epistemically responsible way, and as that condition was spelled out with the Group Responsibilist Condition it follows that a group lacks a justified belief if enough of its operative members should have, but actually fail to, possess further evidence. Thus, because the detectives in Group Epistemic Obligations failed to acquire evidence that they should have acquired, it follows that $\operatorname{ERG}(2)$ is not satisfied. Thus ERG issues the intuitive verdict that the team of detectives lacks a justified group belief in that case.

Fourth, consider the first problem GEAA faced (section 3.1): GEAA prohibited

\footnotetext{
${ }^{27}$ The implicit assumption here is that in our toy group involving three detectives where each are investigative peers within the group, every detective's evidence figures into the total evidence relative to which the group is or is not justified. But as noted above, it might not be in every case that every operative member's evidence figures into the total evidence relative to which the group is or is not justified.
} 
groups from having justified beliefs if all their members failed to properly base their beliefs on their evidence. But we saw that it was possible for a group to properly base its belief on its evidence even when its members failed to properly base their belief on their evidence. So these are cases where, intuitively, the group should have a justified belief in $\mathrm{P}$ while none of their members have a justified belief in P. Notice that ERG(2) together with the Group Responsibility Condition can explain how such cases are possible. For according to ERG(1) and (2) it's possible for a group to justifiedly believe $\mathrm{P}$ so long as the group's total evidence supports $\mathrm{P}$ and the group responsibly believes $\mathrm{P}$. Recall that part of what it is for a group to responsibly believe $\mathrm{P}$ on evidence E according to the Group Responsibilist Condition is for the group to properly base its belief in $\mathrm{P}$ on $\mathrm{E}$. Thus it follows that groups which responsibly believe $\mathrm{P}$ on the basis of $\mathrm{E}$ when their total evidence supports $\mathrm{P}$ also justifiedly believe $\mathrm{P}$ on the basis of $\mathrm{E}$. The fact that a group's members may fail to properly base their belief in $\mathrm{P}$ on $\mathrm{E}$ doesn't compromise this according to ERG. So ERG allows for cases where groups have justified beliefs even when none of its members do due to improper basing. ${ }^{28}$

Fifth, consider the second problem GEAA faced (section 3.2): GEAA prohibited groups from justifiedly believing $\mathrm{P}$ when none of their members believed P. But ERG does not prohibit this so long as the group responsibly believes what its evidence supports. Thus, if it's possible for a group to responsibly believe what its evidence supports while none of its members presently hold the belief (again see section 3.2 for intuitive motivations for this possibility), then ERG will issue the judgement that in such cases groups hold a justified belief. Some might worry that ERG cannot accommodate this because it doesn't make sense to think of a group basing its belief on a piece of evidence when none of its members are doing so. But recall condition (c) of the Group Basing Condition, i.e. the historical condition. According to this, a group's belief in $\mathrm{P}$ can now be based on evidence $\mathrm{E}$ even if none of its members presently have a belief in $\mathrm{P}$; all that is needed is that the group now believes $\mathrm{P}$ on $\mathrm{E}$ because enough of its operative members once based their belief in (/joint commitment to) $\mathrm{P}$ on E. Accordingly, ERG has no trouble accommodating cases

\footnotetext{
${ }^{28}$ This explanation for how ERG avoids GEAA's objection presupposes that the epistemic duties a group's members must satisfy in order for the group to responsibly believe $\mathrm{P}$ doesn't include each member properly basing their belief in $\mathrm{P}$ on their evidence. From this it follows that there are at least some epistemic obligations individuals have (e.g. properly basing their beliefs on their evidence) that are not duties group members have qua group members. Such duties are ones that members can fail to satisfy without necessarily jeopardizing their group's justification. This is another point at which GEAA and ERG diverge. For GEAA requires agents to fulfill all of their individual epistemic obligations.
} 
like Hidden Belief Revisions where it is clear that the corporate board now believes $\mathrm{P}$ on evidence $\mathrm{E}$ because the whole board previously based their belief in $\mathrm{P}$ on $\mathrm{E}$.

Sixth, consider the third problem GEAA faced (section 3.3). Recall the problem was that GEAA(2) had difficulty accounting for cases where there might be some few nearby worlds where sophisticated lines of reasoning unearth counterevidence after a period of deliberation. GEAA is incompatible with groups actually having justified beliefs if there are non-actual nearby worlds where this counterevidence is discovered. But this was seen to be too demanding a condition. ERG does not have this implication. For neither ERG(1) nor ERG(2) makes group justification as extremely sensitive to the ongoings of nearby non-actual worlds as GEAA did. This is clear in the case of the evidentialist condition, ERG(1), which only requires a group's total actual evidence to support believing P. It may be less clear in the case of the responsibilist condition, $\operatorname{ERG}(2)$. So let me explain.

Notice first that ERG(2)'s responsibility condition is explained in terms of a group's members satisfying their G-relevant epistemic duties-see the Group Responsibility Condition. But an individual can satisfy his or her epistemic duties in the actual world even if they fail to do so in some non-actual nearby worlds. For example, if I have a duty to give to charity in the actual world and I do give to charity in the actual world, then I've satisfied that duty in the actual world. The fact that there are some non-actual nearby worlds where I fail to give to charity doesn't entail that I've failed to give to charity in the actual world. The same is intuitively true when it comes to ERG(2)'s proper basing condition. For example, suppose Miss Improper sometimes reasons on the basis of the tea leaves and sometimes she does not: it just depends on whether or not she has time to consult them. Suppose, then, that Miss Improper lacked the time to consult the leaves and because of this she arrived at a belief in Mansour's guilt in the very same way as Miss Proper did. Well, if Miss Improper arrived at her belief in the same way Miss Proper did, then Miss Improper's belief is properly based on her evidence even though there are some nearby non-actual worlds (e.g. worlds where Miss Improper does have the time to consult the tea leaves) where Miss Improper's belief in Mansour's guilt is improperly based. So the satisfaction of $\operatorname{ERG}(2)$ doesn't depend on what happens in nearby non-actual worlds in the way that GEAA does and thus ERG avoids GEAA's problem from section 3.3.

Let's recap. GEAA and ERG have something in common: they are both views of group justification that are evidentialist and responsibilist in spirit. Moreover, both are capable of explaining the intuitive judgements we're inclined to make about the 
concrete cases from section 2. ${ }^{29}$ However, GEAA faced a range of problems outlined in section 3. We've just seen that ERG can avoid each of them. On balance, then, ERG seems like the better view. But even if one remains somewhat unconvinced by the problems of section 3, the fact that ERG seems able to accommodate the same range of cases that GEAA was constructed to accommodate makes ERG at least as plausible a view relative to that range of cases.

\section{References}

Armstrong, D. 1973. Belief, Truth, and Knowledge. Cambridge: Cambridge University Press.

Bird, A. 2014. "When is there a group that knows? Scientific knowledge as social knowledge." In J. Lackey (Ed.), Essays in collective epistemology: 42-63. Oxford: Oxford University Press.

Cohen, J. 1989. "Belief and Acceptance." Mind 98: 367-89.

Gilbert, M. 1987. "Modelling Collective Belief." Synthese 73: 185-204.

Gilbert, M. 1989. On Social Facts. Princeton: Princeton University Press.

Gilbert, M. and D. Pilchman. 2014. "Belief, Acceptance, and What Happens in Groups." In Essays in Collective Epistemology, ed. Jennifer Lackey. Oxford: Oxford University Press.

Goldberg, S. Forthcoming a. "On the Epistemic Significance of Evidence You Should Have Had." Episteme.

Goldberg, S. Forthcoming b. "Should Have Known." Synthese.

Goldman, A. 2009. "The Architecture of Justification." Journal of Philosophy 106: 309-338.

Goldman, A. 2012. Reliabilism and Contemporary Epistemology. Oxford: Oxford University Press.

Goldman, A. 2014. "Social Process Reliabilism: Solving Justification Problems in Collective Epistemology." In Essays in Collective Epistemology, ed. Jennifer Lackey, 11-41. Oxford: Oxford University Press.

Kallestrup, J. Forthcoming. "Group Virtue Epistemology." Synthese.

Lackey, J. 2016. "What is Justified Group Belief?" Philosophical Review 125: 341-396.

\footnotetext{
${ }^{29}$ Again, due to considerations of space and Lackey's previous detailed discussion I didn't explain just how GEAA was able to accommodate these cases.
} 
Millar, A. 1991. Reasons and Experience. Oxford: Oxford University Press.

Quinton, A. 1975. "Social Objects." Proceedings of the Aristotelian Society 76: $1-27$.

Schmitt, Frederick F. 1994. "The Justification of Group Beliefs." In Socializing Epistemology: The Social Dimensions of Knowledge, ed. Frederick F. Schmitt, 257-287. Lanham, MD: Rowman and Littlefield.

Smithies, D. 2015. "Ideal Rationality and Logical Omniscience." Synthese 192: 2769-2793.

Sylvan, K. and Lord, E. Forthcoming. "Believing for Normative Reasons: Prime, Not Composite." in Bondy, P. and Carter, J. A. (eds.) Well-Founded Belief: New Essays on the Epistemic Basing Relation. London: Routledge.

Swain, M. 1988. "Alston's Internalistic Externalism." Philosophical Perspectives 2: 461-473.

Tuomela, R. 1995. The Importance of Us: A Philosophical Study of Basic Social Notions. Stanford University Press.

Tuomela, R. 2004. "Group Knowledge Analyzed." Episteme 1: 109-27.

Turri, J. 2010. "On the Relationship Between Propositional and Doxastic Justification." Philosophy and Phenomenological Research 80: 312-326.

Turri, J. 2011. "Believing For a Reason." Erkenntnis 74: 383-397.

Wedgwood, R. 2014. "Rationality as a Virtue." Analytic Philosophy 55: 319338.

Wedgwood, R. 2012. "Outright Belief." dialectica 66: 309-329.

Weisberg, J. 2016. "Belief in Psyontology." Philosopher's Imprint. 